viding infrastructure that could also be used by their competitors' products. Government, as the custodian of public goods, can also help. Its laws and regulations must be designed to reward businesses for providing public goods. In effect, government is 'outsourcing' its job through incentive-based regulation. To their credit, the authors of Factor Four take on these and other difficult issues, and they recognize the need for greater change beyond 'eco-efficiency'.

Charging Ahead gives a good example of this principle. This book is a definitive description of the US renewable energy industry and an argument for regulatory change to support it. The author has apparently talked to almost everyone involved in the industry, and he includes many fascinating case studies. Although the book is focused on industry in the United States, its value extends beyond that country. The book gives an overview of the industry and the technologies involved. Although it is a snapshot of what was state-of-the-art in 1996, it is comprehensive and clearly written. Even readers with little or no previous knowledge of the subject will be able to follow the author. The case studies themselves with their personal stories of struggle and triumph — yield valuable and basic lessons on entrepreneurship that could be useful in a business-school classroom. Finally, the book provides resources for researchers, including a directory of organizations active in the field.

Businesses today that strive for ecoefficiency often face a trade-off between materials and energy efficiency. For instance, they can use processes that require fewer raw material inputs but are more energyintensive. This results in more greenhousegas emissions and other pollution. Many of the examples given in Factor Four demonstrate this trade-off, a large obstacle to achieving sustainable development through improvements in efficiency.

The root of the problem is that we obtain most of our energy from physical materials such as fossil fuels. The result is that these efficiency improvements simply trade one form of material for another. What if there were a source of energy that did not require pollution or massive materials use? Then we could have energy-intensive industrial processes with no environmental trade-off for high material efficiency. Then both business and society could meet their needs.

Charging Ahead declares that one such source of energy is the Sun. Unfortunately, official and unofficial government subsidies for fossil fuels and nuclear power make it appear that photovoltaics, biomass, wind turbines and other renewable energies derived from the Sun are not as economically attractive. But the fact is that the true cost to society of a gallon of gas is much more than what we pay at the pump. Nevertheless, the author argues that technology is reaching a level where these energy alternatives will soon be inexpensive enough to begin taking over the market. He suggests that the United States should not only eliminate the subsidies given to fossil and nuclear fuels but that it should also begin investing in domestic research in renewables. Otherwise the United States will fall behind in the coming energy revolution. Specific policy recommendations are given.

Charging Ahead provides good examples of profiting through sustainable development. The author argues that the United States can contribute to human development and also gain economically by encouraging business to sell renewable energy technology to the developing world. He describes several businesses that are already doing this on a small scale.

When read together with Factor Four, the message of a radical, profitable and sustainable change comes through loud and clear. Both books provide a challenge to industry and policy-makers to look for the business opportunities in sustainable development.

Robert Day is at the Sustainable Enterprise

Initiative, World Resources Institute, $1709 \mathrm{New}$

York Avenue NW, Washington DC 20006, USA.

\section{Emergent learning}

\section{Connected Knowledge: Science, Philosophy, and Education}

by Alan Cromer

Oxford University Press: 1997. Pp. 221. \$25, $£ 19.99$

\section{Eugenie C.Scott}

Alan Cromer is a man with a mission. A selfdescribed "optimistic know-it-all”, he wants US science education to shape up and abandon constructivism and other trends that he feels are not only failing to educate young Americans but are also mis-educating them. As in his earlier book, Uncommon Sense (Oxford University Press, 1993), he presents science as a non-intuitive way of knowing about phenomena whose causes are not obvious. To learn how the world works requires systematic introduction of principles that build upon one another. Scientific understanding is based on feedback between theory and experience, spiralling up to a more complete understanding of nature. $\mathrm{He}$ blends this philosophy of science with the teaching of science, taking us through quantum physics, the nature of the social sciences, his personal theory of human social organization, a history of education, some idiosyncratic views of learning theory, an even more idiosyncratic commentary on genetics, race, class and IQ, and finally his recommendations for reorganizing US science education.

There is no doubting Cromer's passion and dedication. He has spent several years with Project SEED, an innovative teachertraining programme, as well as developing programmes for teaching basic scientific literacy to prison inmates. He has thought carefully about what high-school graduates should know and about how to design a curriculum to achieve these objectives. His advice flies in the face of some cherished values in US education - which alone recommends the book.

Constructivism, promoted in all reform guidelines on US science education, comes in for a sound thrashing. In constructivist learning, students 'construct' knowledge of science by 'discovering' principles, especially 'learning by exploring. This is thought to result in deeper and more complete understanding. Critical thinking is taught through 'open-ended problems' with either no clear answer or many possible answers.

Wrong reasoning, says Cromer. To learn even the simplest scientific principles (he takes most of his examples from physics) requires the direction of a teacher. "In mucking about randomly, a student learns as little as a mouse does while meandering about the maze on its first trial. Only when the student reaches a goal, such as getting an experiment to agree with an equation, does the whole enterprise begin to make any sense.... An experienced science teacher knows that some detours are so wasteful of time and energy that students should be warned against them, whereas other byways might be left for the students to explore... it may seem far-fetched to compare a student doing a physics experiment with a mouse running through a maze, but only to someone who has never taken a physics laboratory course."

But the term 'constructivism' hides much variation, and I have seen some classroom teachers leading students to understanding in precisely the way Cromer recommends and calling it constructivism. Some constructivist approaches cheerfully if mindlessly exhort the teacher to "accept all answers" instead of reminding them that the point of the exercise is to help the student to understand some principle or other. But some uses of constructivism, such as in pre-assessing a student's understanding (or misunderstanding) of a topic, are certainly worthwhile. There is a place for letting students explore, as Cromer would agree. But for a student to understand either basic principles of science or how science works, the guidance of a teacher is necessary because "without knowledgeable guidance from their teacher, students are truly like mice in a maze. Each will arrive at his own version of the goal with his own set of errors and misconceptions." What is dismal about US education is that most teachers do not understand enough about basic science to be able to supervise such explorations properly, whether called constructivist or something else. 


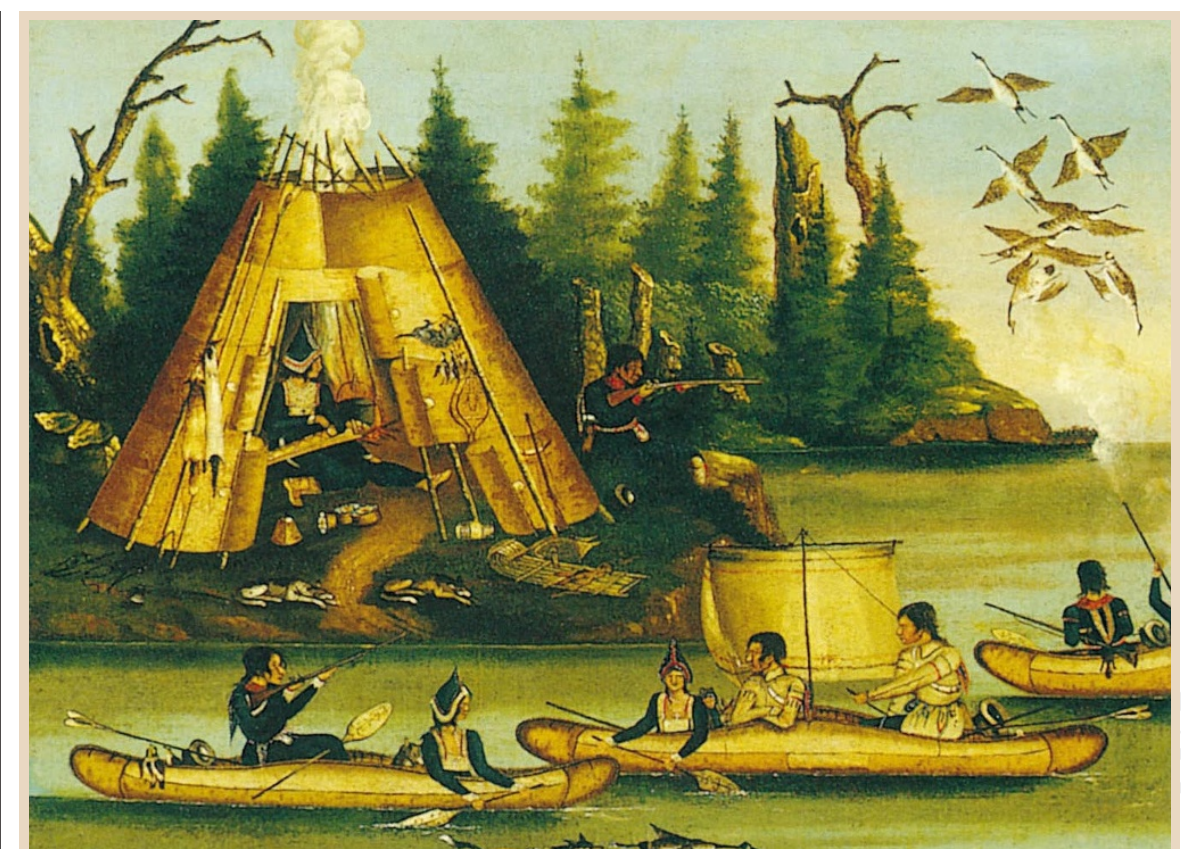

\section{Old companions wholearn new tricks}

Hunting dogs take to the water with their Micmac owners in nineteenth-century Canada. In A History of Dogs in the Early Americas (Yale University Press, \$27.50, £21), Marion Schwartz

So what is Cromer's solution? We must, he says, agree on what high-school graduates should know about science and then develop a coherent curriculum to produce students who have this knowledge. Cromer criticizes the US National Science Education Standards for not accomplishing this task and being laden with educational gobbledegook. A de facto set of ideas and skills already exists, he says, in the 'General Educational Development' test, or GED, a rigorous seven-hour high-school equivalency test of language skills, social studies science and mathematics given to adults. A pass in GED or a highschool diploma is required in the United States to attend college or technical school or to apply for most jobs. A novel idea is to have all ninth-graders take GED before they can go on to the final three years of high schoolor leave school or go into a training programme. "It is vitally important that there be a meaningful intermediate certificate to provide young people with an honorable way to leave school after ninth or tenth grade. The drive to push everyone through twelve years of academic study has made 'drop outs' of those who are unable or unwilling to do so."

To ensure all students get at least to the GED level will require another unfashionable idea - ability grouping, in which students are grouped by their ability to perform certain tasks. Cromer does not intend this to be 'tracking', where students are permanently assigned to high, medium or low IQ groups, but a looser, less-permanent grouping that students can move in and out of as their skills and knowledge improve. $\mathrm{He}$ tells how these versatile companions have coexisted with humans for 12,000 years, whether reared for food, used in hunting, sent to war or revered as guides to the afterlife.

believes ability grouping is especially important iflow-achieving students are to meet the minimal GED-type standards, because these students need special attention to develop even the most basic understanding.

Cromer enjoys the role of curmudgeon, and the forceful way in which he writes cannot help but engage the reader. (Speaking of criticisms of intelligence testing, he growls: "There are few educators who know enough arithmetic to balance a checkbook, let alone understand a multivariant logistic regression analysis".) But this leads to the occasional overstatement that frustrates or annoys. His physics is better than his social science and history. A chapter explaining why the uncertainty and indeterminacy of quantum mechanics makes the visible world in which we live certain and determined is an excellent antidote to postmodernists' claims about the lack of objective reality and the supposed inability of science to explain it. His discussion of intelligence is better than his discussion of race: as a physical anthropologist, I was dismayed by his confusion of the concept of equality with that of identicalness (the former social and legal construct is independent of the latter biological one). He combines the principles of natural selection with observations of animal and human behaviour to produce a new theory of human social organization. Here the yin of hierarchy and loyalty was selected with the yang of individualism and rebelliousness as adaptive traits in early human social environments. Although I am generally sympathetic to sociobiological and evolutionary approaches, I did not find the discussion fully persuasive.

But these are minor glitches in what is certainly a stimulating and thought-provoking book. Although the hats on the good guys and the bad guys are perhaps both whiter and blacker than in reality, one should definitely consider Cromer's analysis. There is a lot to be said for systematically teaching science from the part to the whole.

Eugenie C. Scott is at the National Center for

Science Education, 925 Kearney Street,

El Cerrito, California 94530-2810, USA.

E-mail:scott@natcenscied.org

\section{Fins, legs, fins}

\section{Ancient Marine Reptiles}

edited by Jack M. Callaway and Elizabeth L. Nicholls

Academic: 1997. Pp. 501. \$64.95, £49.95

\section{Michael w. Caldwell}

This book hails itself as the long overdue revision of Samuel Williston's Water Reptiles of the Past and Present (1914). The claim invites comparison. Williston wrote his book by himself; 28 authors, contributing 17 chapters and 6 introductions, have produced Ancient Marine Reptiles. Williston's book was devoted to a taxonomic and biological review of marine reptiles, and not one page described or named a new taxon; four chapters in Ancient Marine Reptiles are purely descriptive, serving only to give names to, or to revise, a single genus or species.

If there is a critical flaw in this edited volume, if there is one feature where it drifts from the tradition of Williston's book, this is it. Simply put, these four chapters should have been published as journal contributions, leaving more space for the remaining 13 synthetic chapters. To my mind, an up-to-date assessment of a particular field should focus on the contrast between observation and theory; innovation is found in the distillation and synthesis of disparate data points and the resulting generation of new questions. It is a pity that there was not more room in this volume to address these contrasts in depth.

Nevertheless, I applaud this volume. Most chapters are well written and pertinent. The figures are informative and the references accurate. Highlights include the chapters by McGowan and by Motani, which provide excellent reviews and interpretations of new faunas and data sets; Rieppel's chapter on Triassic sauropterygians, even though it barely reviews his recent mountain of revisionary publications; and Bell's chapter on mosasaur phylogeny, which unfortunately only scratches the surface of his $\mathrm{PhD}$ thesis, with no discussion of the implications of his character analysis.

The last four chapters, with a lengthy introduction by Massare, reveal the main 